\title{
Could do better: The effectiveness of incentives and competition in schools
}

\author{
Gianni De Fraja ${ }^{a, *}$, Pedro Landeras ${ }^{b}$ \\ ${ }^{a}$ Department of Economics, University of Leicester, Leicester LE1 7RH, United Kingdom \\ ${ }^{\mathrm{b}}$ Department of Economics, University of Cantabria, Avda. Los Castros s/n, 39005, Santander, \\ Cantabria, Spain
}

Received 30 March 2003; received in revised form 27 July 2004; accepted 2 November 2004 Available online 1 August 2005

\begin{abstract}
This paper studies the effects of incentive mechanisms and of the competitive environment on the interaction between schools and students, in a set-up where the students' educational attainment depends on their peer group, on their effort, and on the quality of the school's teaching. We show that increasing the power of the incentive scheme and the effectiveness of competition may have the counterintuitive effect of lowering the students' effort. In a simple dynamic set-up, where the reputation of the schools affects recruitment, we show that more powerful incentives and increased competition lead to segregation of pupils by ability, and may also determine lower attainment in some schools. (C) 2005 Elsevier B.V. All rights reserved.
\end{abstract}

JEL classification: I20; H42

Keywords: Students effort; Schools quality; Peer group effect; Incentives in education; Competition between schools; Quasi-markets

\section{Introduction}

Across the world, reforms of the education system have centred around ideas which the economics literature has identified as essential in improving the performance of commercial organisations, such as the provision of incentives linking individuals' reward to their performance and the creation of vestigial forms of competition between institutions.

* Corresponding author.

E-mail addresses: defraja@le.ac.uk (G. De Fraja), landerascp@munimadrid.es (P. Landeras). 
There are however fundamental differences between commercial organisations and educational institutions (for an exhaustive discussion, see Winston, 1999). The lack of a monetary measure for the performance of the latter is an obvious one, but, no less importantly, education establishments, like schools and universities, use a customer-input technology: the characteristics of the customers affect the quality of the output (Rothschild and White, 1993, 1995). This is true for both of the pupils' ability ${ }^{1}$ and of the effort they exert while at school. ${ }^{2}$

The aim of the paper is to illustrate the consequences of these features of the education process on the way incentive schemes and competitive mechanisms operate. We study the interaction between schools, students, and employers. Employers form expectations on the ability of the school leavers, based on their qualification, and offer them a wage which depends on this expectation. Schools make investments and exert effort, which influence the schools' students' qualifications, both directly, and indirectly, by attracting abler students. Last but not least, the students themselves exert effort while at school, thus affecting their own qualification. As the paper shows, the interaction among these groups of agents is very complex, and it is shaped powerfully, and in often-unexpected ways, by the environment created by the incentive mechanisms and the competitive framework where schools operate, which, in turn, are heavily affected by the government education policy.

Students maximise their expected future earnings, reduced by the cost of effort, and employers maximise expected profits. If these objectives are canonical within economic theory, there is no standard choice for the objective function of schools. The assumption of this paper is that a school aims at maximising the average qualification of its students, reduced by the utility cost of its investments. As any teacher knows, this is realistic, even in the absence of any explicit mechanism linking pay to performance. However, government policy can strengthen the importance of a school's results in the school's objective function, for example, by explicitly linking the teachers' remuneration and chances of promotion with the results obtained by the pupils at their school. ${ }^{3}$

\footnotetext{
${ }^{1}$ This is known as the "peer group" effect: students learn better if they are in a group of abler students. This is a reasonably well-documented phenomenon; see Moreland and Levine (1992) for a survey from a psychology/ education viewpoint, Summers and Wolfe (1977), Henderson et al. (1978) for early economic empirical studies, and Epple et al. (2003) and Zimmer and Toma (2000) for more recent ones. The theoretical analyses of Arnott and Rowse (1987) and de Bartolome (1990) were among the first to take the peer group effect explicitly into account.

${ }^{2}$ Empirical studies rarely include students' effort as an independent input in the education production function: this is probably due to the difficulty of obtaining independent measures of effort. For example, Hanushek's (1992) seminal analysis of the trade-off between quality and quantity of children proxies parental effort with socio-economic status (1992, p. 90). Exceptions are Bonesrønning's (2004) and Cooley (2004). The sociology and education literatures are less scarce; see Fan and Chen (2001) for a meta-analysis of the role of parental effort, and HooverDempsey et al. (2001) for students' effort, measured by homework. At a theoretical level, the literature is equally scarce; the one analysis we are aware of is the undeservingly little noticed paper by Correa and Gruver (1987).

3 There are many examples. In several US states and districts, teachers are offered bonuses and/or salary increases for meeting academic objectives; as an example, a pilot programme in Denver, Colorado, involved 15 schools and 450 teachers, who could receive up to $\$ 1500$ in bonuses, depending on increases in student performance on standardised tests and teacher-developed assessments, and on increases in teachers' skills and knowledge; see BRT and NAB (2001) (see also the US act for school reform, US Congress, 2002). In the UK, the Labour government implemented a performance related pay system for teachers and head teachers (see www.dfee.gov.uk/teachers). In the Australian state of Victoria, union and the state government agreed in 2001 to link teachers' promotions to improvements in student learning monitored via state-wide testing (Victorian Government, 2001). Policy experiments were conducted recently in Israel aimed to measure the responsiveness of students' results to financial incentives for groups (Lavy, 2002a) and for individual teachers (Lavy, 2002b).
} 
In Section 2, we present the actors of the model: students, schools, and employers. In Section 3, we study the benchmark case of an isolated school. Our main conclusion here is that the causal link between the provision of incentives and the educational output is ambiguous: more powerful incentives may have the effect of lowering the effort exerted by the students.

In Section 4, we study two competing schools. Introducing competition, typically by freeing parents from the rigid link between their place of residence and the school attended by their children, is a major plank of many reform proposals. While there are some theoretical analyses of the role of competition between state and private schools (for example Epple and Romano's (1998) study of the effects of a vouchers scheme), and empirical analyses of the effects of competition both between state and private institutions and for institutions within the public sector, ${ }^{4}$ theoretical analyses of competition within the public sector are rare. ${ }^{5}$

An important influence on students' and parents' preferences for schools is the reputation created by the schools' past performance. The simple dynamic model based on this idea in Section 4 shows that reputation can be self-perpetuating: abler children attend the school which performed better in the past, and because this school has abler pupils, it will also perform better in the future, and so on. However, the effects of competition on the student-teacher interaction are ambiguous. It may happen that the school with superior results is in fact the school where students and teachers work less hard: results are better simply because abler students are enrolled. It may also happen that an increase in the power of the incentives reduces the students' attainment. Competition creates segregation by ability: the gap in average ability between the two schools and in their result increases as parents become more responsive to past results.

Our message can therefore be summarised by saying that incentive schemes may backfire and competition may have perverse effects. This may provide an explanation for empirical studies which suggest that putting additional resources into schools may have no impact on results. ${ }^{6}$ To the extent that more powerful incentives are costly - which is the case if teachers are risk averse - then an increase in the power of incentive schemes increases the resources available to schools, while having ambiguous effects on performance. In a naive view of the world, ceteris paribus, additional resources would indeed improve results; but, if the additional resources also affect the trade-offs of the agents participating in the education process, their actions will also change, and therefore, the assumption of ceteris paribus must be abandoned: the potentially offsetting effects

\footnotetext{
${ }^{4}$ For example, Borland and Howsen (1992), Hoxby (1994), and Dee (1998) show that additional competition from private schools improve outcomes for students in public schools in the US. Hoxby (2000) shows that schools choice in the US raises school productivity. Bradley et al. (2001) show that, over the period 1993-1998, competition among secondary state schools in the UK led to increases in efficiency. Furthermore, increased competition is likely to raise teacher quality as suggested by Hanushek and Rivkin (2003).

5 An exception is De Fraja and Iossa (2002). They study the case of competition between two not-for-profit universities located in different towns.

${ }^{6}$ Hanushek (1986) is an influential early survey. More recently, similar results are obtained by Betts (1995), Hanushek (1996), Heckman et al. (1996), and Dearden et al. (2002). Some of these studies are analysed by Card and Krueger (1998), who conclude that "there is some evidence that school resources affect earnings and educational attainment, although much uncertainty remains in the literature" (1998, pp. 39).
} 
operating indirectly via the actions of teachers and students must be included in the determination of the overall effect.

\section{The model}

The education market comprises three groups of agents: students, schools and employers. They are described in detail in the subsections below.

\subsection{Students}

There is a continuum of individuals in the economy, identical in every respect except their ability. This is measured by a unidimensional parameter $\theta \in \mathfrak{R}$, distributed according to a differentiable function $\Phi(\theta)$, with $\Phi^{\prime}(\theta)=\phi(\theta)$, and positive support in an interval $\Theta \in \mathfrak{R}$. The number of individuals is normalised to 1 and their average ability is given by $\bar{\theta}, \bar{\theta}=\int_{\theta \in \Theta} \theta \phi(\theta) \mathrm{d} \theta$.

An individual attends school and, subsequently, enters the labour market. When at school, she exerts effort $e \in E \subseteq \mathfrak{R}$. This measures how diligent she is, how hard she works and so on; it also includes parental effort, such as helping with homework. Effort has a utility cost measured by a function $\psi(e)$, increasing and convex, $\psi^{\prime}(e), \psi^{\prime \prime}(e)>0$. We assume that, while at school, and therefore when she chooses her effort, a student knows the ability distribution of the students enrolled at her school, but has only imperfect information about her own ability. Specifically, we assume that the ability interval $\Theta$ is partitioned in subintervals, $\Theta_{k}$, with $k=1, \ldots, K$, and that students know which ability subinterval they are in, but not the exact value of their ability (for example, they only know whether they are low, medium, high or very high ability, but not their ability relative to the other students in the same ability band). Let $\mu_{k}$ be the measure of interval $\Theta_{k}$, that is, the proportion of the population that has ability in interval $\Theta_{k}: \mu_{k}=\int_{\theta \in \Theta_{k}} \phi(\theta) \mathrm{d} \theta$.

A student leaves school with a qualification, described in detail in Section 2.2, and enters the labour market. Here, she receives a wage, which depends on the employers' expectation of her productivity, which in turn depends on her qualification and the employers' inference about her ability. This is derived below, in Section 2.3. A student's objective function is the maximisation of the difference between expected future wage and effort.

\subsection{Schools}

A school issues its students with a qualification. This is a variable $q$ taking values in a continuum: ${ }^{7} q \in Q \subseteq \mathrm{IR}$. The realised value of $q$ is affected by four factors. The first

\footnotetext{
${ }^{7}$ Qualification is often a discrete variable (for example, in the UK, A/B/C/D/E/F at school and I/IIi/IIii/III/ Ordinary at university). Institutions, however, often distinguish between students who are awarded the same qualification in informal ways, such as providing a transcript of the examination marks, writing reference letters which specify the "quality" of a student's degree, giving the rank in her cohort, and so on.
} 
two may differ from individual to individual: her effort while at school, $e$, and her ability, $\theta$. The other two characterise the school and therefore take the same value for all the students at a given school $i$ : the quality of the teaching $s_{i} \in S \subseteq \Re$, and the average ability of the students in the school, $\bar{\theta}_{i}$ (the "peer group effect"). The variable $s_{i}$ captures the idea that a school can make investments which affects its quality, for example, the quality of buildings, of classroom equipment and computers, the teachers' qualifications; and, also, the teachers' effort in the activities in the classroom, the time they spend to prepare lessons, to assess the students' work, to meet parents, and so on. We assume that, while the school's investments and effort are observable by parents, they are not contractible, and so neither can the school commit itself to a specific level for them prior to enrolling the students, nor can parents or a government agency require the school to make them, or commit to reward the school for undertaking them. The functional relationship between qualification $q$ and the factors affecting it is described in the following.

Assumption 1. A student's qualification is denoted by $q(e, \theta ; s, \bar{\theta})$, and satisfies $q_{e}(\cdot)$, $q_{\theta}(\cdot), q_{s}(\cdot), q_{\bar{\theta}}(\cdot)>0$, and $q_{e e}(\cdot), q_{s s}(\cdot) \leq 0$.

That qualification is deterministic, not restrictive: adding an error term would not alter the results. The positive sign for all the partial first derivatives is natural: ceteris paribus, a student obtains a better qualification who works harder, who is abler, who receives better teaching, and who has abler classmates. The restrictions on the second derivatives are standard decreasing returns assumptions.

A school pursues an objective function which depends positively on the average ${ }^{8}$ qualification of its students and negatively on the teaching effort: ${ }^{9}$

$$
\lambda \int_{\theta \in \Theta} q(e(\theta), \theta ; s, \bar{\theta}) \phi(\theta) \mathrm{d} \theta-\zeta(s) .
$$

In (1), $e(\theta)$ is the average effort level exerted by students of ability $\theta$. The function $\zeta(s)$ is increasing and convex, $\zeta^{\prime}(s), \zeta^{\prime \prime}(s)>0$, implying increasing marginal disutility of effort. $\lambda$ measures the importance of the students' qualification for the school's payoff relative to the cost of effort. Since, as assumed above, the school's effort and investment are not contractible, any reward that the government may wish to offer schools must be made dependent on the qualifications obtained by the students, which, clearly, are contractible. This implies that $\lambda$ is influenced by the government, and this makes it the natural route to study the effects of changes in the power of incentives on the behaviour of the education system. In the rest of this paper, therefore, we view changes in $\lambda$ as policy measures which change the power of the incentives for schools and teachers.

\footnotetext{
${ }^{8}$ Some schools, or their teachers, may have a preference for some of their students, for example, they may derive more utility from increases in the qualification of their brightest pupils. Other schools, vice versa, from increases in the qualification of their weakest pupils. Appropriate weighting of $q(\cdot)$ in (1) would capture this.

9 Size may of course also matter. We prefer to concentrate on students' results and therefore we fix exogenously the size of the schools.
} 


\subsection{Employers}

The focus of our paper is on the interaction between schools and students, so we model the labour market in a stylised way. We assume that an individual's output in the labour market, $\pi$, depends on the qualification obtained at school and on her innate ability: $\pi(q$, $\theta$ ). This relationship is deterministic; adding an error term would not alter the qualitative nature of the analysis. Moreover, there are no externalities or economies of scale in production, so that a worker's output does not depend on the characteristics or the number of her fellow employees.

Assumption 2. An individual's labour market output is denoted by $\pi(q, \theta)$, and it satisfies: $\pi_{q}, \pi_{\theta}(\cdot)>0, \pi_{q q}(\cdot) \leq 0,\left(2 \pi_{q \theta}(\cdot) q_{q}^{-1}(\cdot)+\pi_{\theta \theta}(\cdot)\left[q_{q}^{-1}(\cdot)\right]^{2}+\pi_{\theta}(\cdot) q_{q q}{ }^{-1}(\cdot)\right) \leq 0$.

Ability and qualification affect positively output, the latter at a decreasing rate. The last part of Assumption 2 requires that the output function $\pi(\cdot)$ be sufficiently concave $\left(\pi_{\theta \theta}(\cdot)\right.$ be sufficiently negative) so as to compensate strong complementarity effect between qualification and ability on productivity (a high value of $\pi_{q \theta}(\cdot)$ ) and strong convexity in the inverse relationship between ability and qualification (a high value of $\left.q_{q q}^{-1}(\cdot)\right)$.

Ability is revealed during an individual's working life: we capture this observation with the simplifying assumption that ability is not observed for a (discount rate adjusted) fraction $\beta$ of an individual's working life, and for the rest of the time it is observed by all employers. ${ }^{10}$

There is a competitive labour market: employers bid each worker's wage up until they make zero expected profits from employing that worker. This implies that an individual's wage in the first part of her working life is given by the expected value of her output:

$$
w=\int_{\theta \in \Theta} \pi(q, \theta) f(\theta ; q) \mathrm{d} \theta
$$

where $f(\theta ; q) \in \mathfrak{R}$ is the density of the representative employer's belief about the ability of an individual whose qualification is $q$, the information available at the time that individual is hired. In the second part of the working life, a worker's wage is simply her actual output, $\pi(q, \theta)$.

We study the pure strategy perfect Bayesian equilibria of this game; the restriction to pure strategies is natural in the present set-up. In each stage, players correctly anticipate the actions which will be chosen in the subsequent stages, and they assume that employers' beliefs about the students' ability are consistent with the strategies employed by the students and schools in the previous stages.

Begin the analysis by noting that, in a pure strategy equilibrium, all students in the same ability interval, $\Theta_{k}$, exert the same effort, say $\bar{e}_{k}, k=1, \ldots, K$. This determines a piecewise

\footnotetext{
${ }^{10}$ We let $\pi(q, \theta)$ denote output in both parts of the working life; experience or job specific human capital could be incorporated by having different functional forms in the two parts of the working life, $\pi_{1}(q, \theta)$ and $\pi_{2}(q, \theta)$.
} 


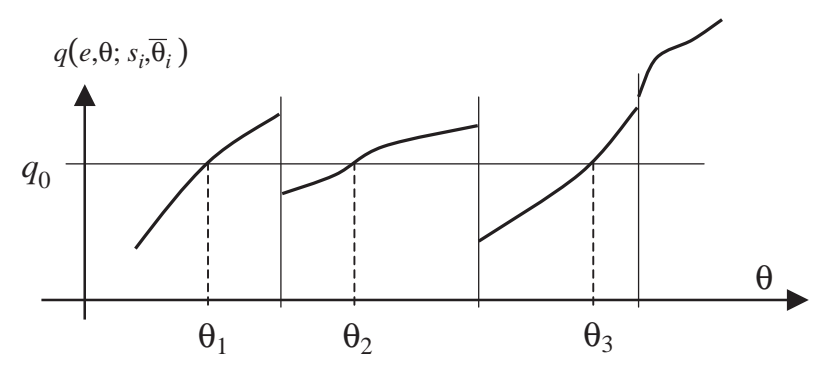

Fig. 1. The relationship between ability and qualification.

continuous relationship between $\theta$ and $q$. For a given qualification $q$, consider the inverse image of $q\left(\bar{e}_{k}, \theta ; s_{i}, \bar{\theta}_{i}\right)$ on the ability space. This is the set:

$$
\left\{\theta \in \Theta \mid \exists k \in\{1, \ldots, K\} \text { s.t.: } q\left(\bar{e}_{k}, \theta ; s_{i}, \bar{\theta}_{i}\right)=q\right\} .
$$

With slight abuse of notation, we denote the set (2) by $q^{-1}\left(\bar{e}_{k}, q ; s_{i}, \bar{\theta}_{i}\right)$. Note that, because $q_{\theta}(\cdot)>0$, there is at most one $\theta$ in $q^{-1}(\cdot)$ in each interval $\Theta_{k}$ : in the example in Fig. 1, if a job applicant has qualification $q_{0}$, then her ability must be one of the values in the set $\left\{\theta_{1}, \theta_{2}, \theta_{3}\right\}$. The requirement that the equilibrium is Bayesian implies two things in this set-up. First, that, if an applicant has qualification $q$, then employers attach zero probability to the event that her ability is $\theta \in \Theta$, unless $\theta \in q^{-1}\left(\bar{e}_{k}, q ; s_{i}, \bar{\theta}_{i}\right)$ for some $\bar{e}_{k}: \theta \notin q^{-1}\left(\bar{e}_{k}, q ; s_{i}, \bar{\theta}_{i}\right\}$ implies $f(\theta ; q)=0$. Second, that for any $\theta \in q^{-1}\left(\bar{e}_{k}, q ; s_{i}, \bar{\theta}_{i}\right)$, employers believe that the probability that a student with qualification $q$ has ability $\theta$ is proportional to the relative frequency of students in interval $\Theta_{k}$ in the set of all students who obtain qualification $q$. Formally, if a student obtains qualification $q$, the employers assessment of her ability is given by:

$$
q^{-1}\left(\bar{e}_{k}, q ; s_{i}, \bar{\theta}_{i}\right) \text { with probability } \frac{\phi\left(q^{-1}\left(\bar{e}_{k}, q ; s_{i}, \bar{\theta}_{i}\right)\right)}{\sum_{k^{\prime}=1}^{K} \phi\left(q^{-1}\left(\bar{e}_{k^{\prime}}, q ; s_{i}, \bar{\theta}_{i}\right)\right)} k=1, \ldots, K .
$$

Note that, having defined the function $\phi$ on the entire real line ensures that all the addenda in the denominator of the probability in (3) are properly defined, though of course they are 0 outside the interval $\Theta$.

Note also that if effort is non-decreasing in ability (that is, if $\bar{e}_{k} \geq \bar{e}_{k-1}$ for $k=2, \ldots, K$ ), then the inverse image set (2) is either empty or a singleton, and therefore, employers can infer exactly a student's ability from her qualification: the mass point of the employers' belief is the true value of a student's ability. In terms of Fig. 1, if effort is non-decreasing in ability, the jumps in the function $q(\cdot)$ at the extremes of the intervals $\Theta_{k}$ are all positive.

\section{A benchmark case: the "monopoly school"}

In this section, we study a school operating in isolation. This is not only a realistic benchmark, applying as it does to all situations where the number and characteristics of the 
students attending a school are exogenously given, but it also constitutes the foundation for the more general case where schools interact with each other, which we study in Section 4.

A student takes as given the effort choice of the school and of all her fellow students, anticipates correctly how employers will behave when offering wages, and maximises her expected wage, net of the utility cost of her effort. Her maximisation problem is stated formally in the next result. Since we have a single school, we drop the school subscript $i$ and the average ability $\bar{\theta}$ in the arguments of the function $q$ in the rest of this section.

Lemma 1. Let $\bar{e}_{k}$ be the average effort exerted by the students in ability interval $\Theta_{k}$, $k=1, \ldots, K$. Let $s$ be the school's effort. The maximisation problem of a student of ability $\theta \in \Theta_{h}$ is given by:

$$
\begin{aligned}
\max _{e \in E} U(e) \equiv & \beta \sum_{k=1}^{K} \int_{\theta \in \Theta_{h}} \pi\left(q(e, \theta ; s), q^{-1}\left(\bar{e}_{k}, q(e, \theta ; s) ; s\right)\right) \frac{\phi(\theta)}{\mu_{h}} \\
& \times \frac{\phi\left(q^{-1}\left(\bar{e}_{k}, q(e, \theta ; s) ; s\right)\right)}{\sum_{k^{\prime}=1}^{K} \phi\left(q^{-1}\left(\bar{e}_{k^{\prime}}, q(e, \theta ; s) ; s\right)\right)} \mathrm{d} \theta+(1-\beta) \int_{\theta \in \Theta_{h}} \pi(q(e, \theta ; s), \theta) \\
& \times \frac{\phi(\theta)}{\mu_{h}} \mathrm{~d} \theta-\psi(e) .
\end{aligned}
$$

Proof. The assumption that the labour market for newly qualified workers is competitive implies that an employer is willing to pay to a student who has qualification $q$ up to her expected output, given her belief. A student with ability in the interval $\Theta_{h}$ exerting effort $e$ will obtain qualification $q(e, \theta ; s)$ with probability $\left(\phi(\theta) / \mu_{h}\right)$ for every $\theta \in \Theta_{h}$. If she does obtain qualification $q(e, \theta ; s)$ she will be believed to have ability $q^{-1}\left(\bar{e}_{k}\right.$, $q ; s)$ with probability $\frac{\phi\left(q^{-1}\left(\bar{e}_{k}, q ; s\right)\right)}{\sum_{k^{\prime}=1}^{K} \phi\left(q^{-1}\left(\bar{e}_{k^{\prime}}, q ; s\right)\right)}, k=1, \ldots, K$. So her assessed ability for exerting
effort $e$ will be

$$
q^{-1}\left(\bar{e}_{k}, q(e, \theta ; s) ; s\right) \text { with probability } \frac{\phi(\theta)}{\mu_{h}} \frac{\phi\left(q^{-1}\left(\bar{e}_{k}, q(e, \theta ; s) ; s\right)\right)}{\sum_{k^{\prime}=1}^{K} \phi\left(q^{-1}\left(\bar{e}_{k^{\prime}}, q(e, \theta ; s) ; s\right)\right)} .
$$

A student's objective is the maximisation of the difference between future expected wage and effort. The former is given by the first two terms in (4), for the two parts of the student's working life, and the latter by the third.

The lemma captures the fact that a student tries to manipulate the signal determined by her qualification, by working, as it were, harder than her colleagues of similar ability, in order to obtain, in the first part of her working life, a higher wage. Of course, in equilibrium, every student tries to do precisely this, and therefore, all students in each 
ability interval exert exactly the same level of effort, so that no student is in fact able to manipulate the signal provided by her qualification. The school's decision of effort is more straightforward: a school takes the effort level of the students as given, and maximises (1).

There can be two types of equilibrium. In one type, all the terms at the denominator of $\frac{\phi\left(q^{-1}\left(\bar{e}_{k}, q ; s\right)\right)}{\sum_{k^{\prime}=1}^{K} \phi\left(q^{-1}\left(\bar{e}_{k^{\prime}}, q ; s\right)\right)}$ are 0 except for $k^{\prime}=k$, and so (4) simplifies to:

$$
\begin{aligned}
\max _{e \in E} U(e) \equiv & \beta \int_{\theta \in \Theta_{h}} \pi\left(q(e, \theta ; s), q^{-1}\left(\bar{e}_{k}, q(e, \theta ; s) ; s\right)\right) \frac{\phi(\theta)}{\mu_{h}} \mathrm{~d} \theta \\
& +(1-\beta) \int_{\theta \in \Theta_{h}} \pi(q(e, \theta ; s), \theta) \frac{\phi(\theta)}{\mu_{h}} \mathrm{~d} \theta-\psi(e) .
\end{aligned}
$$

This happens either if effort is non-decreasing in ability ${ }^{11}$ (implying that for every observed $q$, the inverse image in Fig. 1 is a singleton), or if, when hiring school leavers, employers have the same information as the students (for example because they perform attitudinal tests and interviews, instead of relying exclusively on the observed qualification). In this type of equilibrium, a student in any given ability interval $\Theta_{k}$ competes only against the students in the same ability interval. In the second type of equilibrium, some of the students obtain the same qualification as, and are therefore "confused" by employers with, students in a different ability interval. The algebraic calculations are considerably more complex in this case, though, since it remains the case that all students in the same ability interval exert the same effort, the qualitative features of our results would not be altered. We therefore consider the first type of equilibrium in the rest of the paper. Proposition 1 determines the conditions for existence of the Nash equilibrium and the rest of the section introduces some algebraic simplification to give a graphical analysis of the equilibrium.

Proposition 1. Let Assumptions 1 and 2 hold. The game where the school has the payoff function given in (1), and the students in ability interval $k$ have payoff function given by (5), $k=1, \ldots, K$, has at least one Nash equilibrium.

Proof. Existence of at least one Nash equilibrium follows from standard arguments (Fudenberg and Tirole, 1991, p 34). A Nash equilibrium exists if each player has a compact and convex strategy space and a payoff function which is continuous in all its arguments and quasi-concave in a player's own strategy. The strategy spaces are closed intervals of the real line, $S \subseteq \mathfrak{R}$ for schools, and $E \subseteq \mathfrak{R}$ for students, and are therefore compact and convex. Payoff functions are clearly continuous; quasi-concavity of the school's payoff function follows immediately from $q_{s s}(\cdot)<0$ and $\zeta^{\prime \prime}(s)>0$. As to the

\footnotetext{
${ }^{11}$ Empirically, this is likely to be the relevant case. For example, the UK NCDS dataset contains a set of variables that can be used as proxies for students' effort as well as educational tests of individual's ability. De Fraja et al. (2004) use this dataset to construct an index of student effort, which has correlation with the ability index of 0.7570 or 0.4422 , depending on whether effort is treated as exogenous or not.
} 
students, differentiating (5) twice and re-arranging (details available on request), we can write

$$
\begin{aligned}
U^{\prime \prime}(e)= & \int_{\theta \in \Theta_{h}} q_{e e}(\cdot)\left[\beta \pi_{q}(\cdot)+\beta \pi_{\theta}(\cdot) q_{q}^{-1}(\cdot)+(1-\beta) \pi_{q}(\cdot)\right]+\left[q_{e}(\cdot)\right]^{2}\left[\pi_{q q}(\cdot)\right. \\
& \left.+\beta\left[2 \pi_{q \theta}(\cdot) q_{q}^{-1}(\cdot)+\pi_{\theta \theta}(\cdot)\left[q_{q}^{-1}(\cdot)\right]^{2}+\pi_{\theta}(\cdot) q_{q q}^{-1}(\cdot)\right]\right] \frac{\phi(\theta)}{\mu_{h}} \mathrm{~d} \theta .
\end{aligned}
$$

Assumptions 1 and 2 ensure that the above is negative in the entire strategy space, thus completing the proof.

Having established existence in a general set-up, to perform some comparative statics on the equilibrium, we resort to the standard graphical tool of the best reply functions; in order to keep the algebra at a manageable level, we choose the following specific functional form for $q$ :

$$
q\left(e, \theta ; s_{i}, \bar{\theta}_{i}\right)=(e+\theta) g\left(s_{i}, \bar{\theta}_{i}\right),
$$

where $g(s, \bar{\theta})>0$ satisfies $g_{s}(\cdot), g_{\theta}(\cdot)>0$ and $g_{s s}(\cdot), g_{\theta \theta}(\cdot)<0$. In this formulation, a student's qualification is proportional to her individual characteristics, effort and ability. Note that, in the absence of any natural scale to measure these variables, taking their sum amounts to little more than a normalisation. The coefficient of proportionality is given by the school's characteristics, the teaching quality $s_{i}$ and the average ability of the pupils, $\bar{\theta}_{i}: g(\cdot)$ is therefore a measure of the school's quality. In view of the functional form (6), the objective function of the school (1) can be written as:

$$
\lambda(\bar{e}+\bar{\theta}) g(s, \bar{\theta})-\zeta(s),
$$

where $\bar{e}$ is the average effort exerted by the school's students.

The best reply functions are obtained by drawing the iso-utility maps for the two types of agents. To draw them, we determine first the effect of a change in the school's characteristics on the effort exerted by the representative student in ability interval $\Theta_{h}$.

Lemma 2. Let (6) hold. Let $\bar{e}_{h}$ be the average effort level exerted by the students with ability $\theta \in \Theta_{h}$. Let $e$ be the solution of the maximisation problem of a student of ability $\theta \in \Theta_{h}$. If $\psi^{\prime \prime}\left(\bar{e}_{h}\right)>\int_{\theta \in \Theta_{h}} g(s)\left[\pi_{q q}(\cdot) g(\cdot)+\pi_{\theta q}(\cdot)\right] \phi(\theta) \mathrm{d} \theta$, then $e=\bar{e}_{h}$ implies $\left(\right.$ de $\left./ d_{\bar{e}_{h}}\right)<1$.

Proof. Total differentiation of the first order condition of (5) yields:

$$
\frac{\mathrm{d} e}{\mathrm{~d} \bar{e}_{h}}=\frac{\int_{\theta \in \Theta_{h}}\left[\pi_{q \theta}(\cdot) g(s)+\pi_{\theta \theta}(\cdot)\right] \phi(\theta) \mathrm{d} \theta}{U^{\prime \prime}(e)},
$$

where

$$
U^{\prime \prime}(e)=\int_{\theta \in \Theta_{h}}\left\{g(s)\left[\pi_{q q}(\cdot) g(\cdot)+2 \pi_{\theta q}(\cdot)\right]+\pi_{\theta \theta}(\cdot)\right\} \phi(\theta) \mathrm{d} \theta-\psi^{\prime \prime}(e)<0 .
$$


For (8) to be less than 1 , it must be:

$$
\begin{aligned}
& \int_{\theta \in \Theta_{h}}\left[\pi_{q \theta}(\cdot) g(s)+\pi_{\theta \theta}(\cdot)\right] \phi(\theta) \mathrm{d} \theta>\int_{\theta \in \Theta_{h}}\left\{g(s)\left[\pi_{q q}(\cdot) g(\cdot)+2 \pi_{\theta q}(\cdot)\right]+\pi_{\theta \theta}(\cdot)\right\} \\
& \quad \times \phi(\theta) \mathrm{d} \theta-\psi^{\prime \prime}(e) .
\end{aligned}
$$

which establishes the Lemma.

Lemma 2 allows us to determine diagrammatically the equilibrium value of $\bar{e}_{h}$ in a Cartesian diagram with $\bar{e}_{h}$ and $e$ on the axes. Note that $e\left(\bar{e}_{h}\right)$ can rigorously be interpreted as the best reply function of an individual student in the subgame where all students in ability group $h$ choose their effort: given that the rest of the students of her ability group exert effort level $\bar{e}_{h}, e\left(\bar{e}_{h}\right)$ is that student's optimal response. At the intersection with the $45^{\circ}$ line, where $e=\bar{e}_{h}$, the student exerts the average effort level, and so every student will also do so. When $\left(\mathrm{d} e / \mathrm{d} \bar{e}_{h}\right)<1$ the solid curve in Fig. 2 intersects the $45^{\circ}$ line from above, as depicted. The condition required for the term $\left(\mathrm{d} e / \mathrm{d} \bar{e}_{h}\right)$ to be less than 1 is weak: essentially, it is satisfied as long as the second cross derivative $\pi_{q \theta}(\cdot)$ is not "too high", that is, if the effect of qualification on productivity does not raise "too much" with ability. In what follows, we assume it to be satisfied. The diagram can be used to illustrate the effect of a change in the school's characteristics, $g(s)$, on the effort exerted by the representative student in ability interval $\Theta_{h}$. Total differentiation of the first order condition of (5) gives:

$$
\frac{\mathrm{d} e}{\mathrm{~d} g(s)}=\frac{\int_{\theta \in \Theta_{h}}\left[\pi_{q}(\cdot)+\left[\pi_{q q}(\cdot) g(s)+\pi_{\theta q}(\cdot)\right](e+\theta)\right] \phi(\theta) \mathrm{d} \theta}{-U^{\prime \prime}(e)} .
$$

If this is positive (negative), then the curve $e\left(\bar{e}_{h}\right)$ moves up (down) as a consequence of an increase in $g$, as depicted by the dashed (dotted) locus in Fig. 2.

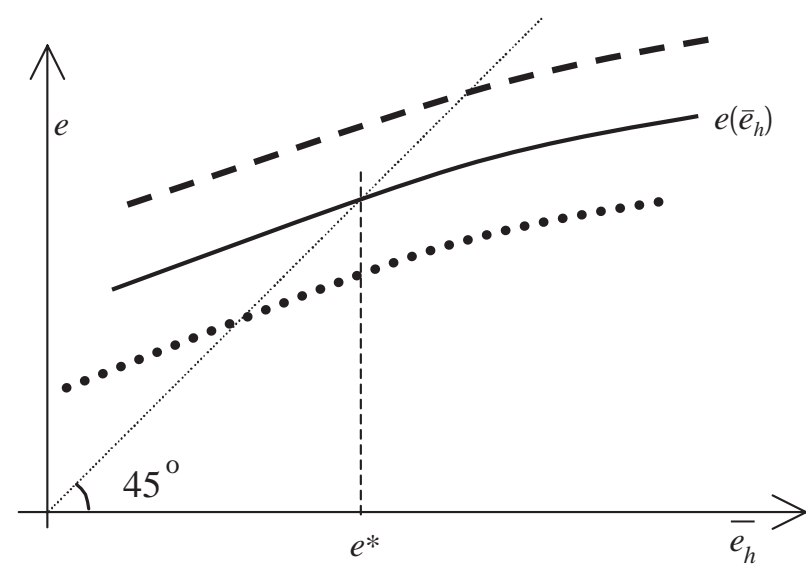

Fig. 2. The equilibrium of the game among students. 
The above can have either sign: when it is positive, the curve $e\left(\bar{e}_{h}\right)$ moves up, as depicted by the dashed locus in Fig. 2, and we can say that school quality and students' effort are complements. There is a kind of "multiplier" effect of an increase of a school's quality: a better school increases the marginal benefit of a student's effort, making it worthwhile for her to work harder, in order to improve her signal to the market. If one student works harder, then all students do. This increase in students' effort enhances the improvement in qualification due to the increase in the schools' teaching quality. If instead the sign of (10) is negative, school quality and students' effort are substitutes: an increase in $g$ brings about a downward shift of the curve $e\left(\bar{e}_{h}\right)$ to the dotted locus and therefore a reduction in students' effort. Students respond to an increase in the school quality by reducing their own effort, which (partially) offsets the beneficial effect of increased school quality (for a similar, informal discussion, see Bonesrønning, 2004, p. 2).

We are now ready to study the interaction between the school and its students. Even though all students in the same ability group behave in the same way, and their behaviour can be described by a representative student, we are still left with the interaction among $K+1$ players. Each player is characterised by a best reply function, giving the best action for every feasible combinations of actions of the other players. In a well-behaved problem, the intersection of the $K+1$ best reply functions is a set of isolated points, the Nash equilibria, and at least one of them exists in view of Proposition 1. The diagrammatic depiction of this interaction can be obtained by studying a given ability group, and taking the effort levels of all other ability groups as given. ${ }^{12}$ Consider therefore group $h$. Total differentiation of (5) gives, after substitution of $e=\bar{e}_{h}$ :

$$
\begin{aligned}
& {\left[\int_{\theta \in \Theta_{h}}\left[g(s) \pi_{q}\left(\left(\bar{e}_{h}+\theta\right) g(s), \theta\right)+\beta \pi_{\theta}\left(\left(\bar{e}_{h}+\theta\right) g(s), \theta\right] \frac{\phi(\theta)}{\mu_{k}} \mathrm{~d} \theta-\psi^{\prime}\left(\bar{e}_{h}\right)\right] \mathrm{d} \bar{e}_{h}\right.} \\
& \quad+\left[g^{\prime}(s) \int_{\theta \in \Theta_{h}} \pi\left(\left(\bar{e}_{h}+\theta\right) g(s), \theta\right) \frac{\phi(\theta)}{\mu_{k}} \mathrm{~d} \theta\right] \mathrm{d} s=0 .
\end{aligned}
$$

And therefore:

$$
\left.\frac{\mathrm{d} s}{\mathrm{~d}_{\bar{e}_{h}}}\right|_{U=\text { constant }}=\frac{\int_{\theta \in \Theta_{h}}\left[g(s) \pi_{q}(\cdot)+\beta \pi_{\theta}(\cdot)\right] \phi(\theta) \mathrm{d} \theta-\psi^{\prime}\left(\bar{e}_{h}\right)}{-g^{\prime}(s) \int_{\theta \in \Theta_{h}} \pi(\cdot) \phi(\theta) \mathrm{d} \theta} .
$$

At an equilibrium, the second order conditions will be satisfied, as argued in Proposition 1, and therefore the numerator is positive for "low" $\bar{e}_{h}$, and negative for "high"

\footnotetext{
${ }^{12}$ Formally, we are considering the projection of the best reply functions (which are subsets of the $(K+1)$ dimensional space given by the Cartesian product of the strategy spaces of the school and each of the groups of students, namely, $S \times E^{K}$ ) onto the two-dimensional space given by the Cartesian product of the strategy space of the school and of students with ability in the interval $\theta_{h}, S \times E$.
} 

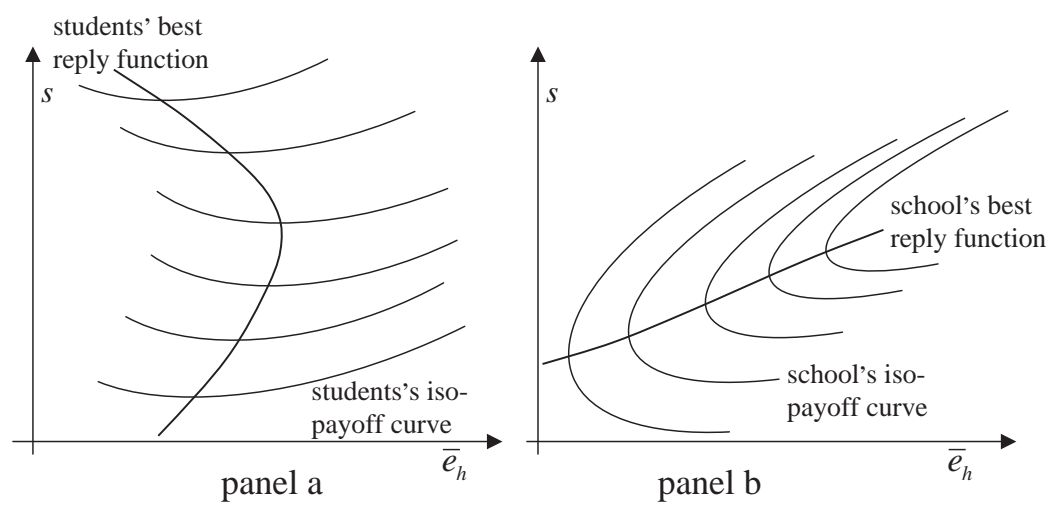

Fig. 3. The indifference map and the best reply function of the students (panel a) and the school (panel b).

$\bar{e}_{h}$. The denominator is negative, and so the iso-utility loci of the students in interval $\Theta_{h}$ are decreasing for $\bar{e}_{h}$ lower than the stationary point, increasing otherwise. The stationary points, at the various utility levels, determine the highest iso-utility that can be reached at any given level of the school's quality (for given effort level of the students in all other ability intervals), that is the students' best reply function. Totally differentiate the first order condition of (5), and substitute $e=\bar{e}_{h}$ :

$$
\begin{aligned}
\frac{\mathrm{d} \bar{e}_{h}}{\mathrm{~d} s} & =\frac{\mathrm{d} \bar{e}_{h}}{\mathrm{~d} e} \frac{\mathrm{d} e}{\mathrm{~d} g(s)} g^{\prime}(s), \\
\frac{\mathrm{d} \bar{e}_{h}}{\mathrm{~d} \lambda} & =0 .
\end{aligned}
$$

The students' best reply function has slope given the sign of (11). This is the same as the sign of $(\mathrm{d} e / \mathrm{d} g(s))$, the response of an individual student to changes in the school's characteristics, which is given in (10). It is increasing if school's quality and students' effort are complements, decreasing if they are substitutes.

We have drawn Fig. 3 in the heuristically plausible case in which they are complements for low values of $s$ (and hence $g(s)$ ) and substitutes for higher values of $s$ and $g(s)$ : note that $g(s)$ is the coefficient of the negative term $\pi_{q q}(\cdot)$ in the numerator of (10); clearly other shapes are possible. Next consider the school. Taking as given the effort level of all other ability intervals, we can depict the isopayoff loci in the $\left(\bar{e}_{h}, s\right)$ Cartesian space. Totally differentiating the school's payoff we get:

$$
\left.\frac{\mathrm{d} s}{\mathrm{~d} \bar{e}_{h}}\right|_{U_{s}=\mathrm{constant}}=\frac{-\lambda g(s)}{\lambda\left(\bar{e}_{h}+\bar{\theta}\right) g_{s}(s)-\zeta^{\prime}(s)},
$$



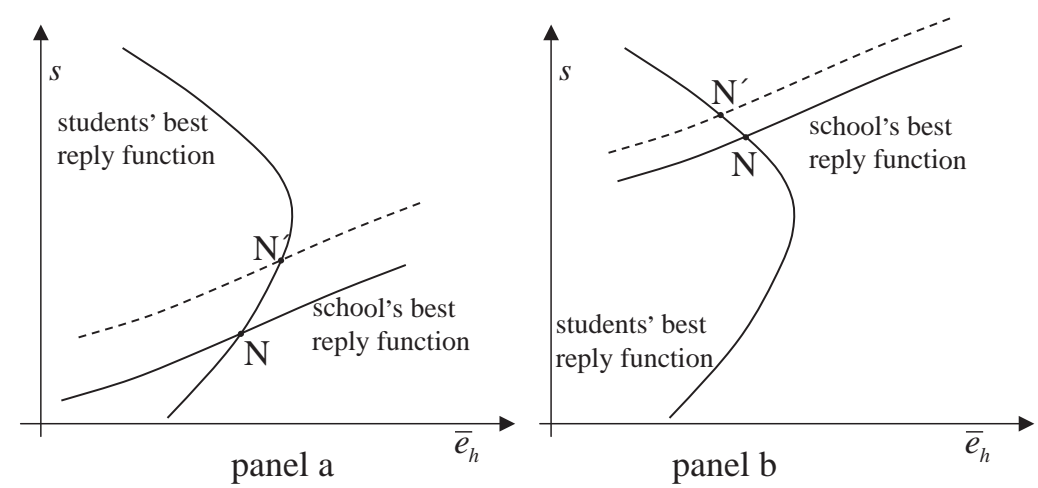

Fig. 4. Effects of changes in $\lambda$ on the Nash equilibrium: efforts are complements (panel a) and substitutes (panel b).

$U_{s}$ denotes the utility of the school. Again, this is decreasing for "low" $s$, and increasing otherwise. Total differentiation of the school's first order condition for the choice of $s$ yields:

$$
\begin{aligned}
\frac{\mathrm{d} s}{\mathrm{~d} \bar{e}_{h}} & =\frac{\lambda g_{s}(s)}{-\left(\lambda(\bar{e}+\bar{\theta}) g_{s s}(s)-\zeta^{\prime \prime}(s)\right)}>0, \\
\frac{\mathrm{d} s}{\mathrm{~d} \lambda} & =\frac{(\bar{e}+\bar{\theta}) g_{s}(\cdot)}{-\left(\lambda(\bar{e}+\bar{\theta}) g_{s s}(\cdot)-\zeta^{\prime \prime}(s)\right)}>0 .
\end{aligned}
$$

The diagrams in the two panels of Fig. 3 can be overlapped to obtain the Nash equilibrium $^{13}$ of the game. This is shown as point $N$ in Fig. 4, which depicts the intersection of the best reply curves, and describes the effects on the Nash equilibrium of an increase in $\lambda$, the power of the incentive schemes. From (12), we see that the students' best reply function does not move, and, from (15), that the school responds to an increase in $\lambda$ with an increase in $s$ : the school's best reply curve shifts up and the equilibrium moves from point $N$ to point $N^{\prime}$. Effects of changes in $\lambda$ on the Nash equilibrium: efforts are complements (panel a) and substitutes (panel b).

The effect of a change in $\lambda$ on the equilibrium depends on whether the students' best reply function is upward or downward sloping. If the school's quality and the students' effort are complements then, as shown in panel (a) in Fig. 4, both the school's and the students' effort increase, and so, clearly, will the average qualification of the students: strengthening incentives makes teachers and students work harder and improves results. This is consistent with Lavy's (2002b) empirical findings: he studies a policy experiment in Israeli schools, and finds that teachers improve their effort in response to financial

\footnotetext{
${ }^{13}$ The assumption of a Nash equilibrium implies a dual causality direction between school's characteristic and children's (and parents') effort. This is in line with Bonesrønning's (2004) finding that class size (a characteristic of the school) affects parental effort and is confirmed by the analysis of De Fraja et al., 2004.
} 

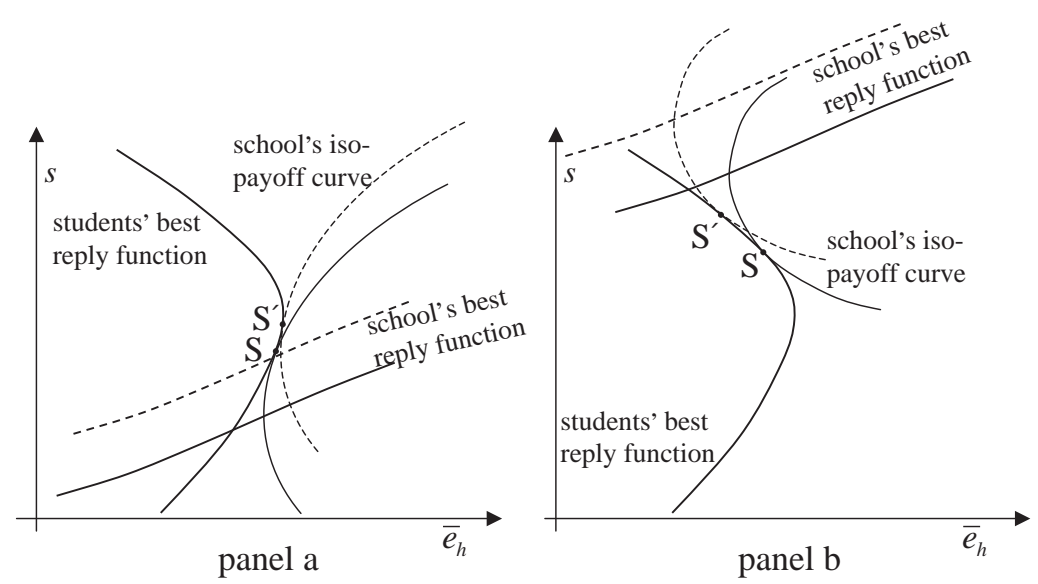

Fig. 5. Effects of changes in $\lambda$ on the Stackelberg equilibrium: efforts are complements (panel a) and substitutes (panel b).

incentives, and that students' attainment improves as a result. However, if the school's and the students' effort are substitutes, as shown in panel (b), then the best reply function of the students is sloping backwards, and the students' effort decreases in response to an increase in $\lambda$, and the overall effect on attainment is not as strong as the increase in the school's effort would suggest. ${ }^{14}$

The diagrammatic analysis is only suggestive in the case when there are several ability intervals; the school will choose an average best response level of effort; nevertheless, if for all groups the effort levels of schools and students are complements (substitutes), then an increase in $\lambda$ will have the same qualitative response as depicted in Fig. 4.

The solution concept of Nash equilibrium assumes that the school and the students choose simultaneously. This may not be the appropriate assumption when the school's effort is constituted by activities which are fixed before the students choose their effort, such as investments in the quality of buildings, classroom equipment, computers, sporting facilities, teachers' qualifications and so on. The appropriate solution concept in this case is Stackelberg equilibrium ${ }^{15}$, which can also be obtained from the diagrams in Fig. 3. The school chooses the point on its best iso-payoff locus, keeping into account that the students will choose a point on their best reply function. This is depicted in Fig. 5. It is also

\footnotetext{
${ }^{14}$ Note that the level of attainment at the equilibrium $N^{\prime}$ is higher than at point $N$ in both panels in Fig. 5. In order for the attainment to be lowered by an increase in $\lambda$, it would need to be the case that, at their intersection, the school's best reply function is steeper that the students' best reply function. In this case, an increase in $\lambda$ would unambiguously decrease both the students' and the school's effort, and therefore the students' attainment. A brief reflection suggests however that this equilibrium would not be "stable" under plausible adjustment mechanisms and will be disregarded in what follows.

${ }^{15}$ Overlapping the diagrams which depict the iso-utility curves, it is immediate to verify that both the school and the students would benefit if they could find a way to commit to higher levels of effort, as shown by Correa and Gruver (1987). This is the case irrespective of whether the school's and the students' efforts are substitutes or complements, and is the case both in the Nash and in the Stackelberg equilibrium.
} 
straightforward to show that an increase in $\lambda$ also increases the slope of the school's isopayoff loci.

$$
\frac{\mathrm{d}}{\mathrm{d} \lambda}\left(\frac{\mathrm{d} s}{\mathrm{~d} \bar{e}_{h}}\right)=\frac{g(s) \zeta^{\prime}(s)}{\left(\lambda\left(\bar{e}_{h}+\bar{\theta}\right) g_{s}(s)-\zeta^{\prime}(s)\right)^{2}} .
$$

The effects of changes in $\lambda$ on the indifference map and on the best reply function are depicted as the dotted lines in Fig. 5. As in the Nash equilibrium case, the school's effort increases with the power of the incentives, and the students' effort increases (decreases) if school's and students' effort and complements (substitutes): the comparison between Figs. 3 and 4 suggests that, in our set-up, the precise timing of the school's choice does not affect the qualitative features of the effects of changes in the power of the incentive schemes.

\section{A simple dynamic model of school competition}

Competition among schools has typically taken the form of allowing students to apply to a school of their (or their parents') choice. Endogenising the set of students who apply to a given school, in the absence of infinitely elastic supply of school places, and of course in the absence of a price system, implies that rules must be in force to determine which students gain admission when a school has fewer available places than applications. Unless the admission procedure is rigorously beyond the school's control, to the extent that their payoff depends on the average qualification and that the latter depends on the ability of its students, schools may rationally try to improve their average qualification by recruiting abler students. ${ }^{16}$

In this section, we investigate this possibility. Specifically, we assume that students can choose which schools to apply for and that they make their choice on the basis of the observed values of the schools' past examination results. ${ }^{17}$ The number of places is given, and if a school is oversubscribed, it can, to some extent, select higher ability applicants. We assume that schools can imperfectly observe ability: there is a partition of the interval $\Theta$ such that the school can observe in which interval a particular applicant is. Note that it

\footnotetext{
${ }^{16}$ This is precisely what happened with the introduction of competition in New Zealand. According to Fiske and Ladd (2000, pp. 216-223), schools attempted successfully to select pupils from socially advantaged backgrounds: "the system quickly flip-flopped [...] from one in which parents and children choose schools to one in which schools choose students" (Fiske and Ladd, 2000, p. 9, our emphasis).

${ }^{17}$ This is in line with the stylised facts of the operation of the quasi-market for education, even though, for prospective pupils, the school's characteristics ought to be more meaningful indicators. In the UK, the publication of school's league tables has indeed been an important source of information for parents, and one that has clearly affected the intake in schools. Gibbons and Machin (2003) have documented the effects of the rankings obtained form these tables on house prices in England and Wales. In response to the criticism that, as our model suggests, examination results are strongly affected by the quality of the school's intake, from 2003, league tables include a measure of the improvement obtained by its students while at school.
} 
is not necessary that the school's partition be the same as the students': as long as there are at least two sub-intervals, the school is able to affect the average ability of its intake, even if it has a coarser partition of the ability interval $\Theta$ than the students have. Formally, we assume that time is divided into periods, and that, in each period, the average ability of the pupils enrolled at school $i$ depends on the difference between the average ${ }^{18}$ qualification obtained by the students at the two schools in the previous period (this may be due to the preferences of the new cohorts of students, or even to students changing schools from 1 year to the next). Formally, in period $t, t=1,2, \ldots$, the average ability of the students who are enrolled in school $i, \bar{\theta}_{i, t}$, is given by an increasing function of the difference in the schools' average examination results:

$$
\bar{\theta}_{i, t}=h\left(\bar{q}_{i, t-1}-\bar{q}_{j, t-1}\right), h^{\prime}(\cdot)>0, \quad i, j=1,2, j \neq i,
$$

where $\bar{q}_{i, t-1}$ is the average qualification of the students attending school $i$ in period $t-1$. Note that (17) implies $h(0)=\bar{\theta}$ : if the two schools obtain the same average result in one period, they both have ability equal to the population average in the next period. Eq. (17) also implies $h(y)+h(-y)=2 \bar{\theta}$ : the function $h$ is symmetric. Note that $h^{\prime}(0)$ can be taken as a measure of the speed with which parents respond to past differences in results, and is in general affected by government policy regarding the ease with which children can choose schools and the information available to parents. We assume that schools maximise the current period payoff. ${ }^{19}$

Let $Q\left(\bar{\theta}_{i}\right)$ denote the reduced form average qualification of the students attending a school where the average ability is $\bar{\theta}_{i}$ :

$$
Q\left(\bar{\theta}_{i}\right)=g\left(s^{*}\left(\bar{\theta}_{i}\right), \bar{\theta}_{i}\right)\left(\overline{\mathrm{e}}^{*}\left(\bar{\theta}_{i}\right)+\bar{\theta}_{i}\right),
$$

where $\bar{e}^{*}\left(\bar{\theta}_{i}\right)$ and $s^{*}\left(\bar{\theta}_{i}\right)$ are the reduced form effort levels exerted at the Nash equilibrium of the period game by students and the school when the average ability in the school is $\bar{\theta}_{i}$ (given by the simultaneous maximisation of (4) and (1)). In period $t$, the average ability of the students in the two schools is given by:

$$
\begin{aligned}
& \bar{\theta}_{1, t}=h\left(Q\left(\bar{\theta}_{1, t-1}\right)-Q\left(2 \bar{\theta}-\bar{\theta}_{1, t-1}\right)\right), \\
& \bar{\theta}_{2, t}=2 \bar{\theta}-\bar{\theta}_{1, t}
\end{aligned}
$$

\footnotetext{
18 This is a simplifying assumption. Other moments of the distribution may matter to parents, and parents whose children have different abilities may care differently from different regions of the distribution of qualifications: parents of bright children may be interested in the highest qualifications obtained by children at their school, and parents of less bright children may be more interested in how well weak children perform.

19 That is, decision makers in schools have a discount factor of 0 . This allows us to treat each period as a separate game and eliminates the possibility of equilibria of the repeated game based on trigger strategies. We feel justified in this assumption by the fact that the focus of this paper is on the interaction between schools, and not on the role of time preferences on the behaviour of schools. Since such preferences are likely to be important in practice, because teachers may stay in a school for longer than a cohort of students, further research should take rigorously into account the possibility that the interaction between schools is best described by a repeated game.
} 
Note that $\bar{\theta}_{1, t}=\bar{\theta}\left(=\bar{\theta}_{2, t}\right)$ is always a steady state solution of the differential Eq. (18). Whether this solution is locally stable depends on the stability condition:

$$
h^{\prime}(\leq 0)\left(2 Q^{\prime}(\bar{\theta})\right)<1
$$

Therefore, if $Q^{\prime}(\bar{\theta}) 0$, that is if an increase in the average ability brings about lower schools and/or students' effort which more than compensates for the increase in average ability, the symmetric equilibrium, $\bar{\theta}_{1, t-1}=\bar{\theta}_{2, t-1}=\bar{\theta}$, is locally stable. In the more realistic case in which $Q^{\prime}(\bar{\theta})>0$, it is worth illustrating formally a simple but important consequence of (20).

Proposition 2. For any given $Q^{\prime}(\bar{\theta})>0$, there exists $h^{*}>0$ such that, if $h^{\prime}(0)>h^{*}$, then the symmetric equilibrium is not stable.

That is, for effective enough competition, if there are stable equilibria, they are asymmetric. Less formally, competition generates segregation. This conclusion is in line with the empirical analysis of Bradley and Taylor (2002), who find that the UK recent reforms, which have increased parental choice with regard to the school attended by their children, have also led to greater segregation of pupils.

The complex interaction between a school and its students described in Section 3 makes it extremely hard to derive further qualitative results, either algebraically or geometrically, on the features of these asymmetric equilibria. We therefore find examples of these asymmetric equilibria using simple specific functional forms and numerical simulations. ${ }^{20}$ In the present set-up, this is not a weakness, as we intend to illustrate the variety of possible outcomes of the competitive process among schools: with more general functional forms the ambiguity would in general increase.

We therefore let:

$$
\begin{aligned}
& \pi(q, \theta)=q+\theta-\frac{1}{2} q^{2}-\frac{\rho}{2} \theta^{2}+\alpha q \theta, \rho \geq 0, \alpha \in(-1,1), \\
& g\left(s_{i}, \bar{\theta}_{i}\right)=u s_{i}+(1-u) \bar{\theta}_{i}, \quad u \in(0,1), \\
& \psi(e)=\frac{\gamma}{2} e^{2}, \gamma>0, \\
& \zeta(s)=\frac{\sigma}{2} s^{2}, \sigma>0 .
\end{aligned}
$$

In (21), $\rho$ measures the "relative concavity" of qualification and ability in the output function (note that having the same linear coefficient for $q$ and $\theta$ is a normalisation); $\alpha$ indicates the strength of the complementarity (if $\alpha>0$ ), or of the substitutability (if $\alpha<0$ ) between qualification and ability. In (22), $u$ measures the relative importance of the school's effort and the peer group in the schools' quality, and in (23) and (24), $\gamma$ and $\sigma$ are

\footnotetext{
20 The computer programme is available on request from the authors.
} 
measures of the marginal cost of effort for schools and students, respectively. In addition, we also assume that the function $h$ is given by

$$
h(y)=\bar{\theta}+\frac{\left(\bar{\theta}_{\max }-\bar{\theta}_{\text {min }}\right) \arctan (\delta y)}{\pi} .
$$

While unusual, the algebraic expression (25) has a natural shape. $\bar{\theta}_{\max }$ and $\bar{\theta}_{\min }$ denote the average ability in the two schools in the event of complete segregation by ability, when all the students whose ability is above the median are in the same school. Eq. (25) implies that these can be reached only as the difference between the average qualifications in the two schools tends to $\infty$. The parameter $\delta$ is $h^{\prime}(0)$ in (17). For simplicity, we also have set $K=1$, so that all students in the same school exert the same level of effort.

Table 1 illustrates the long run stable equilibrium for two sets of simulations, where $\lambda$ increases in each set, given the values of the other parameters. We have obtained the steady-state values by starting from the initial average ability pair $(1 / 2+\varepsilon, 1 / 2-\varepsilon)$, and running the dynamical system until the difference between the ability in each school in successive time periods fell below a preset threshold. In the table, a grey column denotes a decreasing variable. We assumed that the interaction between schools and students within each period is given by the Nash equilibrium; as illustrated above, using the Stackelberg equilibrium instead would not alter the qualitative features of the solution.

In Table 1 , as $\lambda$ increases, the symmetric equilibrium ceases to be stable and the gap in intake between the schools increases; this pattern is common to all the simulations we have ran: increasing the power of incentives increases segregation. This is natural:

Table 1

Effects of changes in the power of incentives on the equilibrium of the dynamic game

\begin{tabular}{lllllllll}
\hline$\lambda$ & $\bar{q}_{1}$ & $\bar{q}_{2}$ & $\bar{\theta}_{1}$ & $\bar{\theta}_{2}$ & $s_{1}$ & $s_{2}$ & $e_{1}$ & $e_{2}$ \\
\hline Table & $1 \mathrm{a}: \quad \alpha=0.1$, & $\delta=10, \rho=0.3, u=0.9$, & $\sigma=10, \gamma=10$ & & & \\
\hline 1 & 0.0585 & 0.0585 & 0.5000 & 0.5000 & 0.0536 & 0.0536 & 0.0953 & 0.0953 \\
2 & 0.0883 & 0.0883 & 0.5000 & 0.5000 & 0.1080 & 0.1080 & 0.1000 & 0.1000 \\
3 & 0.1759 & 0.0731 & 0.6272 & 0.3728 & 0.1975 & 0.1288 & 0.1043 & 0.1043 \\
4 & 0.2443 & 0.0789 & 0.6635 & 0.3365 & 0.2779 & 0.1599 & 0.1086 & 0.1076 \\
5 & 0.3102 & 0.0877 & 0.6828 & 0.3172 & 0.3577 & 0.1926 & 0.1122 & 0.1107 \\
6 & 0.3751 & 0.0980 & 0.6949 & 0.3051 & 0.4374 & 0.2261 & 0.1151 & 0.1137 \\
7 & 0.4392 & 0.1091 & 0.7032 & 0.2968 & 0.5168 & 0.2604 & 0.1171 & 0.1165 \\
Table & $1 \mathrm{~b}: \alpha=-0.6, \delta=10, \rho=0.9, u=0.9, \sigma=5, \gamma=3$ & & & \\
\hline 1.5 & 0.1514 & 0.1514 & 0.5000 & 0.5000 & 0.1871 & 0.1871 & 0.1930 & 0.1930 \\
1.55 & 0.1555 & 0.1550 & 0.5008 & 0.4992 & 0.1935 & 0.1932 & 0.1927 & 0.1933 \\
1.6 & 0.1709 & 0.1476 & 0.5365 & 0.4635 & 0.2059 & 0.1931 & 0.1786 & 0.2069 \\
1.65 & 0.1798 & 0.1467 & 0.5510 & 0.4490 & 0.2149 & 0.1965 & 0.1726 & 0.2124 \\
1.7 & 0.1876 & 0.1468 & 0.5616 & 0.4384 & 0.2233 & 0.2004 & 0.1681 & 0.2166 \\
1.75 & 0.1948 & 0.1476 & 0.5702 & 0.4298 & 0.2314 & 0.2046 & 0.1642 & 0.2199 \\
2 & 0.2267 & 0.1549 & 0.5991 & 0.4009 & 0.2697 & 0.2276 & 0.1500 & 0.2314 \\
3 & 0.3299 & 0.2000 & 0.6456 & 0.3544 & 0.4105 & 0.3272 & 0.1146 & 0.2516 \\
4 & 0.4133 & 0.2505 & 0.6623 & 0.3377 & 0.5394 & 0.4293 & 0.0868 & 0.2585 \\
5 & 0.4821 & 0.3010 & 0.6697 & 0.3303 & 0.6581 & 0.5306 & 0.0615 & 0.2593 \\
6 & 0.5390 & 0.3497 & 0.6726 & 0.3274 & 0.7678 & 0.6299 & 0.0382 & 0.2559 \\
7 & 0.5864 & 0.3956 & 0.6732 & 0.3268 & 0.8694 & 0.7263 & 0.0169 & 0.2496
\end{tabular}


when the symmetric equilibrium is unstable, then a small initial difference in achievement is amplified by the actions of the participants: the stable equilibrium is at a point where, within each school, the combined marginal cost of effort (of schools and students) exactly balances the marginal benefit of effort. We saw earlier that the students' payoff functions are unaffected by changes in $\lambda$, whereas the school' marginal benefit of an increase in $\lambda$ is given by $(\bar{e}+\bar{\theta}) g(s, \bar{\theta})$. This increases with the average ability, and therefore it makes the schools' and the students' effort more responsive to an increase in $\lambda$, and increases the marginal benefit of increases in the "combined" effort (note that how this increase in the combined effort is shared out between schools and students will depend, as argued in Section 3, on the complementarity or substitutability of the effort of the two groups of players: in Table 1a, both efforts increase, in Table 1b, only the schools'). Notice also that, in Table 1a, students and teachers work harder in the better school, whereas, in Table $1 \mathrm{~b}$, teachers work harder in the better school while students work less hard. When $\lambda$ is such that the schools are not very different in intake, an increase in $\lambda$ has opposite effects on the qualification of the two schools: the "better" school responds to an increase in $\lambda$ with an improvement in the qualification, the other school with a reduction (in Table $1 \mathrm{~b}$ this happens for a smaller range of values for $\lambda$ ). This pattern is illustrated in Fig. 6 which shows the average qualification in the two schools as a function of $\lambda$, and is caused by the reduction in the average ability of the intake, accompanied by the possible reduction in the school's effort illustrated in the seventh column in Table $1 \mathrm{~b}$.

In Table 2, we consider the effects of changes in $\delta$, the effectiveness of competition between schools. The general message is that the effects of competition on schools are ambiguous and possibly counter-productive. This is in line with McMillan (2004), who, in a model of competition between private and state schools, finds that competition may lower the effort exerted by the state schools. The stratification by ability identified in Proposition 2 strengthens with $\delta$. But, as the table indicates, the main reason why the students' attainment improves in one school and worsens in the other is the change in intake. Indeed, there is a wide variety of patterns with regard to effort, as shown in the last

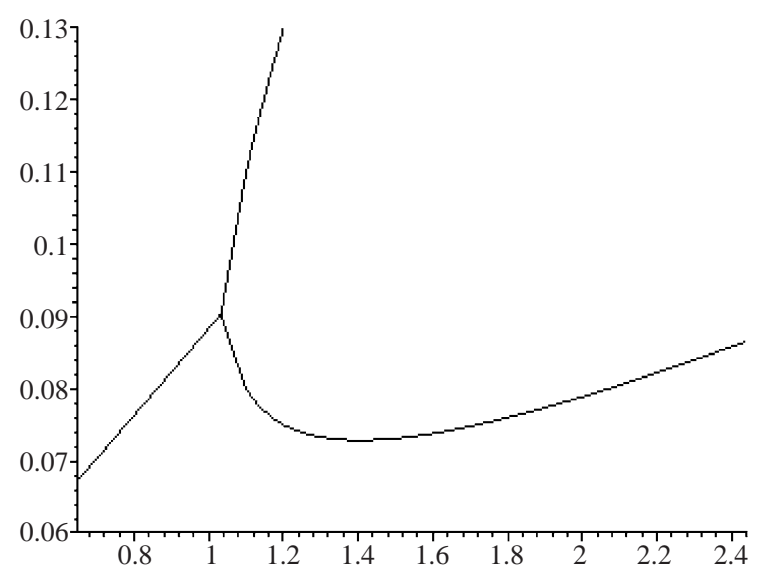

Fig. 6. Value of the average qualification in the two schools. 
Table 2

Effects of changes in the effectiveness of competition on the equilibrium of the dynamic game

\begin{tabular}{|c|c|c|c|c|c|c|c|c|}
\hline$\delta$ & $\bar{q}_{1}$ & $\bar{q}_{2}$ & $\bar{\theta}_{1}$ & $\bar{\theta}_{2}$ & $s_{1}$ & $s_{2}$ & $e_{1}$ & $e_{2}$ \\
\hline \multicolumn{9}{|c|}{ Table 2a: $\alpha=1, \lambda=5, \rho=0.3, u=0.5, \sigma=10, \gamma=5$} \\
\hline 3 & 0.2857 & 0.2857 & 0.5000 & 0.5000 & 0.2031 & 0.2031 & 0.3125 & 0.3125 \\
\hline 5 & 0.4705 & 0.1485 & 0.6615 & 0.3385 & 0.2563 & 0.1515 & 0.3637 & 0.2677 \\
\hline 7 & 0.5130 & 0.1268 & 0.6936 & 0.3064 & 0.2670 & 0.1416 & 0.3744 & 0.2598 \\
\hline 9 & 0.5332 & 0.1174 & 0.7084 & 0.2916 & 0.2720 & 0.1370 & 0.3794 & 0.2563 \\
\hline \multicolumn{9}{|c|}{ Table $2 \mathrm{~b}: \quad \alpha=0.1, \lambda=5, \rho=0.3, u=0.5, \sigma=10, \gamma=5$} \\
\hline 3 & 0.2490 & 0.2490 & 0.5000 & 0.5000 & 0.1824 & 0.1824 & 0.2296 & 0.2296 \\
\hline 5 & 0.3577 & 0.1583 & 0.6247 & 0.3753 & 0.2134 & 0.1505 & 0.2287 & 0.2269 \\
\hline 7 & 0.4058 & 0.1274 & 0.6745 & 0.3255 & 0.2254 & 0.1376 & 0.2272 & 0.2249 \\
\hline 9 & 0.4267 & 0.1154 & 0.6954 & 0.3046 & 0.2304 & 0.1321 & 0.2263 & 0.2240 \\
\hline \multicolumn{9}{|c|}{ Table 2c: $\alpha=0.1, \lambda=5, \rho=0.9, u=0.5, \sigma=10, \gamma=5$} \\
\hline 3 & 0.2235 & 0.2235 & 0.5000 & 0.5000 & 0.1674 & 0.1674 & 0.1696 & 0.1696 \\
\hline 5 & 0.2922 & 0.1632 & 0.5912 & 0.4088 & 0.1876 & 0.1468 & 0.1592 & 0.1784 \\
\hline 7 & 0.3497 & 0.1232 & 0.6604 & 0.3396 & 0.2026 & 0.1309 & 0.1499 & 0.1842 \\
\hline 9 & 0.3723 & 0.1096 & 0.6863 & 0.3137 & 0.2081 & 0.1250 & 0.1462 & 0.1862 \\
\hline \multicolumn{9}{|c|}{ Table $2 \mathrm{~d}: \quad \alpha=0.1, \lambda=5, \rho=0.9, u=0.5, \sigma=10, \gamma=0.7$} \\
\hline 5 & 0.7204 & 0.7204 & 0.5000 & 0.5000 & 0.4001 & 0.4001 & 1.1006 & 1.1006 \\
\hline 7 & 0.7972 & 0.6335 & 0.6358 & 0.3642 & 0.3890 & 0.4094 & 0.9200 & 1.2735 \\
\hline 9 & 0.8158 & 0.6088 & 0.6716 & 0.3284 & 0.3858 & 0.4114 & 0.8715 & 1.3174 \\
\hline 11 & 0.8251 & 0.5960 & 0.6899 & 0.3101 & 0.3841 & 0.4124 & 0.8466 & 1.3395 \\
\hline \multicolumn{9}{|c|}{ Table 2e: $\alpha=0.1, \lambda=5, \rho=0.6, u=0.3, \sigma=10, \gamma=0.8$} \\
\hline 2 & 0.6992 & 0.6992 & 0.5000 & 0.5000 & 0.2473 & 0.2473 & 1.1484 & 1.1484 \\
\hline 4 & 0.8803 & 0.5016 & 0.6571 & 0.3429 & 0.2472 & 0.2410 & 0.9910 & 1.2635 \\
\hline 6 & 0.9216 & 0.4518 & 0.6957 & 0.3043 & 0.2464 & 0.2382 & 0.9472 & 1.2840 \\
\hline 8 & 0.9380 & 0.4314 & 0.7115 & 0.2885 & 0.2460 & 0.2370 & 0.9288 & 1.2915 \\
\hline
\end{tabular}

four columns of Table 2. Taking Table $2 \mathrm{a}$ as the base case, we note that the increase in the effectiveness of competition increases the average ability in the better school, and, when $\alpha$, the complementarity between ability and qualification in the output function is sufficiently high, it provides incentives for the provision of effort by both students and the school in the better school, and vice versa, gives a disincentive in the school with the lower ability intake. In the rest of the Table, $\alpha$ is set at a lower level. In Table $2 b$, this implies that students in the better school lower their effort in response to the increase in the quality of their peer group. In Table $2 \mathrm{c}, \rho$, which measures the rate of decrease in the return to ability, is very high. Here, as the weak school becomes worse, its students work harder and harder, in order not to lose too much when they enter the labour market. In Table $2 \mathrm{~d}$, in addition to the high rate in the decrease in ability, there is also a lower marginal disutility of the students' effort (low $\gamma$ ). Consequently, in response to the lowering of the peer group quality, they increase effort much more strongly than with the parameter values in Table 2c: this increases the school's marginal benefit to the point where the school's effort itself increases with the intensity of competition. Note that, with this parameter combination, we 
have the striking conclusion that results improve in the better school and worsen in the weaker school as competition becomes more effective, despite the fact that both students and teachers work more in the weaker school and less in the better school. Finally, in the last part of Table 2, the schools' effort is relatively less important than the peer group for the school's quality (low $u$ ), and while both schools reduce their effort, only the students in the weaker schools work harder.

\section{Concluding remarks}

The paper studies the effects of incentives in the education sector and competition between education institutions. A school's students' results depend on their own effort in learning and on the school's investment and teaching effort which are directly affected by the incentives provided to schools, and by the competitive environment in which schools operate.

The main message of the paper is simply put: the strategic interaction among the participants in the education process may make incentives backfire and competition have perverse effects. ${ }^{21}$ For example, students may reduce their effort when teachers increase theirs; this may dampen the effect of increases in the power of incentives on results. When schools interact with one another, their attempts to attract the better students further complicates the relationship between agents, to the point, as we show with robust and plausible functional forms and parameter combinations, that increases in the power of incentives and in the effectiveness of competition may reduce students' attainment. These effects emerge even in our simplified set-up. For example, our analysis assumes that the provision of incentives to schools and teachers is not beset by the problems that the literature has classified under the "gaming" label (see Prendergast, 1999, especially pp. 2329 for a survey of the theoretical and the empirical literature): to the extent that the incentives are more powerful in one direction than in another, agents will rationally exert more effort in that direction. Adding this possibility, which is clearly very important in an education context, would further strengthen our message that incentives have potentially unpredictable effects. To the extent that incentives are costly, our analysis may be interpreted as providing a theoretical underpinning for the ambiguous relationship between resources and results which some literature has identified (e.g., Hanushek, 1986).

From a policy perspective, at the very least, our paper illustrates the importance of further theoretical research to understand the interaction between schools and students, and the role of the institutional design in this interaction, before designing the competitive environment and reforming the incentive mechanisms for schools. Learning by trial and errors can have very large costs for the cohorts of students who find themselves in the "trial" period of a new system. The book by Fiske and Ladd (2000) illustrates this point

\footnotetext{
${ }^{21}$ Some empirical evidence from the third world confirms the potential ambiguity of direct incentives to teachers: in Kenya, long-term attainment did not improve as a consequence of a programme offering teachers substantial incentives (Glewwe et al., 2003), and, in India, while private schools improved performance as a consequence of performance related pay, state schools did not (Kingdon and Teal, 2002). Similar results to the latter are found by Ballou for the US (2001).
} 
exemplarily, describing in vivid detail the stratification of schools by ability of their intake that an effective mechanism for school competition brought about in New Zealand, as theorised by our model. Hsieh and Urquiola's (2003) analysis of the highly competitive environment in which Chilean schools have operated since 1981, also suggests that schools tried to attract better students, but that the educational attainment did not improve. Yet another example comes from the UK, where the publication of league tables which assisted very effectively the competitive process among schools, has only recently included a "value added" measure (measuring the gap between initial intake and final results), precisely because policy makers perceived that information based only on examination results would induce schools to try to attract students more likely to obtain good examination results. In the specific, our analysis has implication for the thorny issue of selection by schools: should schools be allowed to choose their pupils? Section 4 suggests caution in this respect: in conjunction with competition between schools, selection by ability may well have counterproductive effects, increasing segregation, and lowering the effort exerted by teachers and students: this, moreover, would not be shown in any data, since the schools would maintain and improve their results even when their effort and their students' effort are lowered.

A more general suggestion from our analysis is that it may be preferable to try to influence effort directly, rather than trying to do so indirectly via incentive mechanisms for schools and teachers; this would sidestep the problems caused by the possible substitutability of students' and teachers' effort. Along these lines is noteworthy a policy recently piloted in the UK, whereby 16 year olds from deprived backgrounds are offered direct financial incentives to stay on at school beyond the compulsory age (Dearden et al., 2003). The understanding of the determinants of the effort exerted by the participant in the education process is clearly essential to ensure that any policies of this type obtain their goal: (De Fraja et al., 2004) is a first step in this direction.

\section{Acknowledgement}

We wish to thank Dieter Bös, Massimo Florio, Steve Machin, José María Pérez de Villarreal, Steve Pischke, the co-editor, Thomas Piketty, and especially two referees of this journal for helpful comments on earlier drafts. Part of this research was carried out while Gianni De Fraja was visiting the University of Rome "Tor Vergata". The paper was presented at the 2002 Congress of the European Economic Association in Venice, and at seminars at the Centre for the Economics of Education at LSE, at the University of Rome "Tor Vergata", and at the University of Milan "Bicocca".

\section{References}

Arnott, Richard, Rowse, John, 1987. Peer group effects and educational attainment. Journal of Public Economics $32,287-305$.

Ballou, Dale, 2001. Pay for performance in public and private schools. Economics of Education Review 20, $51-61$. 
Betts, Julian, 1995. Does school quality matter? Evidence from the national longitudinal survey of youth. Review of Economics and Statistics 77, 231-252.

Bonesrønning, Hans, 2004. The determinants of parental effort in education production: do parents respond to changes in class size? Economics of Education Review 23, $1-9$.

Borland, Melvin V., Howsen, Roy M., 1992. Student academic achievement and the degree of market concentration in education. Economics of Education Review 11, 31-39.

Bradley, Steve, Taylor, Jim, 2002. The effect of the quasi-market on the efficiency-equity trade-off in the secondary school sector. Bulletin of Economic Research 54, 295-314.

Bradley, Steve, Geraint, Johnes, Millington, J., 2001. The effect of competition on the efficiency of secondary schools in England. European Journal of Operational Research 135, 545-568.

BRT, NAB, 2001. Pay for Performance in Education. An Issue Brief for Business Leaders. The Business Roundtable and National Alliance of Business, New York.

Card, David, Krueger, Alan, 1998. School resources and student outcomes. Annals of the American Academy of Political and Social Science 559, 39-53.

Cooley, Jane, 2004. Equilibrium Achievement Under Conformity Effects. Department of Economics, Duke University.

Correa, Hector, Gruver, Gene W., 1987. Teacher-student interaction: a game theoretic extension of the economic theory of education. Mathematical Social Sciences 13, 19-47.

Dearden, Lorraine, Ferri, Javier, Meghir, Costas, 2002. The effect of school quality on educational attainment and wages. Review of Economics and Statistics 84, 1-20.

Dearden, Lorraine, Emmerson, Carl, Frayne, Christine, Meghir, Costas, 2003. "The impact of financial incentives on education choice," Presented at the CEPR meeting, The Economics of Education, Paris.

de Bartolome, Charles, 1990. Equilibrium and inefficiency in a community model with peer group effects. Journal of Political Economy 98, 110-133.

Dee, Thomas S., 1998. Competition and the quality of public schools. Economics of Education Review 17, 419-427.

De Fraja, Gianni, Iossa, Elisabetta, 2002. Competition among institutions and the emergence of the elite university. Bulletin of Economic Research 54, 275-293.

De Fraja, Gianni, Oliveira, Tania, Zanchi, Luisa, 2004. Must Try Harder. Evaluating the role of Effort on Examination Results. University of York, Department of Economics.

Epple, Dennis, Romano, Richard E., 1998. Competition between private and public schools, vouchers and peer group effects. American Economic Review 88, 33-62.

Epple, Dennis, Romano, Richard E., Sieg, H., 2003. Peer effects financial aid and selection of students to colleges and universities: an empirical analysis. Journal of Applied Econometrics 18, 501-525.

Fan, Xitao, Chen, Michael, 2001. Parental involvement and students' academic achievement: a meta-analysis. Educational Psychology Review 13, 1-22.

Fiske, Edward B., Ladd, Helen F., 2000. When Schools Compete: A Cautionary Tale. Brookings Institution Press, Washington.

Fudenberg, Drew, Tirole, Jean, 1991. Game Theory. MIT Press, Cambridge, MA.

Gibbons, Steve, Machin, Stephen, 2003. Valuing English primary schools. Journal of Urban Economics 53, $197-219$.

Glewwe, Paul, Ilias, Nauman, Kremer, Michael, 2003. Teacher Incentives. National Bureau of Economic Research, DP 9671, New York.

Hanushek, Eric A., 1986. The economics of schooling: production and efficiency in public schools. Journal of Economic Literature 23, 1141-1177.

Hanushek, Eric A., 1992. The trade-off between child quantity and quality. Journal of Political Economy 100, $84-117$.

Hanushek, Eric A., 1996. Schools resources and student performance. In: Burtless, Gary (Ed.), Does Money Matter? The Effect of School Resources on Student Achievement and Adult Success. The Brookings Institution, Washington, pp. 43-73.

Hanushek, Eric A., Rivkin, Steve G., 2003. Does public school competition affect teacher quality. In: Hoxby, Caroline Minter (Ed.), The Economics of School Choice. University of Chicago Press, Chicago, pp. $23-47$. 
Heckman, James, Layne-Farrar, Anne, Todd, Petra, 1996. Does measured school quality really matter? An examination of the earnings-quality relationship. In: Burtless, Gary (Ed.), Does Money Matter? The Effect of School Resources on Student Achievement and Adult Success. The Brookings Institution, Washington, pp. $192-289$.

Henderson, Vernon, Mieszkowski, Peter, Sauvageau, Yvon, 1978. Peer group effects in educational production function. Journal of Public Economics 10, 97-106.

Hoover-Dempsey, Kathleen V., Battiato, Angela C., Walker, Joan M.T., Reed, Richard P., DeJong, Jennifer M., Jones, Kathleen P., 2001. Parental involvement in homework. Educational Psychologist 36, 195-209.

Hoxby, Caroline M., 1994. Do Private Schools Provide Competition for Public Schools. National Bureau of Economic Research DP 4978, New York.

Hoxby, Caroline M., 2000. Does competition among public schools benefit students and taxpayers? American Economic Review 90, 1209-1238.

Hsieh, Chang-Tai, Urquiola, Miguel, 2003. When Schools Compete, How Do they Compete? An Assessment of Chile's Nationwide School Voucher Program. National Bureau of Economic Research DP 10008, New York.

Kingdon, Geeta, Teal, Francis, 2002. "Does performance related pay for teachers improve student performance? Some evidence from India," The Centre for the Study of African Economies Working Paper Series, 165.

Lavy, Victor, 2002a. Evaluating the effect of teachers' group performance incentives on pupil achievements. Journal of Political Economy 110, 1286-1317.

Lavy, Victor, 2002b. Paying for Performance: The Effects of Teachers' Financial Incentives on Students' Scholastic Outcomes. The Hebrew University of Jerusalem.

McMillan, Robert, 2004. Competition, incentives, and public school productivity. Journal of Public Economics, $1871-1892$.

Moreland, Richard L., Levine, John M., 1992. The composition of small groups. In: Lawler, E.J., Markovsky, B., Ridgeway, C., Walker, H. (Eds.), Advances in Group Processes, vol. 9. JAI Press, Greenwich, CT, pp. $237-280$.

Prendergast, Canice, 1999. The provision of incentive in firms. Journal of Economic Literature 37, 7-63.

Rothschild, Michael, White, Lawrence J., 1993. The university in the marketpalce: some insights and some puzzles. In: Clotfelter, Charles T., Rothschild, Michael (Eds.), Studies of Supplies and Demand in Higher Education. University of Chicago Press, Chicago.

Rothschild, Michael, White, Lawrence J., 1995. The analytics of pricing in higher education and other services in which customers are inputs. Journal of Political Economy 103, 573-586.

Summers, Anita A., Wolfe, Barbara L., 1977. Do schools make a difference? American Economic Review 67, 639-652.

US Congress, 2002. No Child Left Behind Act. US Department of Education, Washington, DC.

Victorian Government, 2001. "Schools Agreement 2001," The Department of Education, Employment and Training. School Staffing Series. State of Victoria.

Winston, Gordon, 1999. Subsidies, hierarchy and peers: the awkward economics of higher education. Journal of Economic Perspectives 13 (1), 13-36.

Zimmer, Ron W., Toma, Eugenia F., 2000. Peer effects in private and public schools across countries. Journal of Policy Analysis and Management 19, 75-92. 